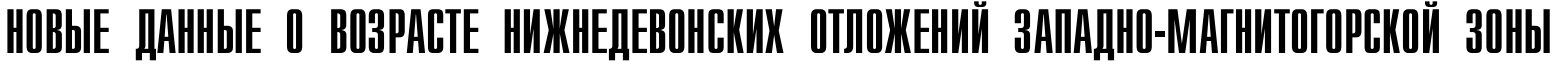 НОЖНОГО УРАЛА
}

\author{
Р. И. Зайнуллин ${ }^{1}$ Л. И. Мизенс ${ }^{2}$, А. Г. Мизенс² \\ ${ }^{1}$ Институт геологии УФИЦ РАН, Уфа; zri-bgu@mail.ru \\ ${ }^{2}$ Институт геологии и геохимии УрО РАН, Екатеринбург; mizensAG@igg.uran.ru
}

\begin{abstract}
Нижнедевонские отложения Западно-Магнитогорской зоны Южного Урала в разных районах представлены мансуровской, ильтибановской, ускульской и рыскужинской толщами. По причине макроскопической схожести, недостаточности биостратиграфических данных и сложного тектонического строения территории долгое время данные толщи рассматривались в составе ирендыкской свиты. После принятия в 1993 году новой Стратиграфической схемы Урала и проведения на изучаемой территории геолого-съемочных работ, было установлено, что они являются возрастными аналогами мазовской свиты нижнего девона. По результатам детальных стратиграфических исследований и геологического изучения девонских разрезов В. А. Масловым и О. В. Артюшковой было принято решение рассматривать нижнедевонские толщи в виде самостоятельных единиц.

Ускульская толща расположена в Узынкырской подзоне Западно-Магнитогорской зоны (юго-западный берег оз. Ускуль и северо-западный склон одноименной горы Республики Башкортостан). Сложена она вулканокластическими, карбонатными и кремнистыми породами, реже вулканитами. Видимая мощность разреза составляет примерно 700 м. Долгое время возраст ускульской толщи определялся по фауне из линзовидных известняков, расположенных в верхней части разреза. В статье приведены первые находки макрофауны из ритмичной пачки тефротурбидитов, залегающих в нижней части разреза. Фауна представлена остатками брахиопод и криноидей. Брахиоподы соответствуют раннедевонскому пражско-эмсскому возрасту. Новые данные позволяют говорить о близком времени формирования тефротурбидитов с вышележащими известняками и определяют возраст ускульской толщи в целом как пражско-раннеэмсский с учетом данных по конодонтам.
\end{abstract}

Ключевые слова: нижний девон, биостратиграфия, макрофауна, Магнитогорская мегазона, Южный Урал.

\section{NEW DATA ON AGE OF LOWER DEVONIAN DEPOSITS OF THE WEST-MAGNITOGORSK ZONE OF THE SOUTHERN URALS}

\author{
R. I. Zaynullin1, L. I. Mizens², A. G. Mizens ${ }^{2}$ \\ ${ }^{1}$ Institute of Geology (Federal Ufa Research Centre) RAS, Ufa \\ ${ }^{2}$ Zavaritsky Institute of Geology and Geochemistry UB RAS, Ekaterinburg
}

Lower Devonian deposits of the West-Magnitogorsk zone of the Southern Urals in some regions are represented by Mansurovo, Iltibanovo, Uskul' and Ryskuzhino strata. For a long time these strata were considered as a part of the Irendyk suite due to the macroscopic similarity, insufficiency of biostratigraphic data and complicated tectonic structure of the territory. After the adoption a new Stratigraphic scheme of the Urals in 1993 and the geological survey, carried out in the study area, the age identity with the Lower Devonian Mazovo suite was established. Based on the results of detailed stratigraphic and geological studies of the Devonian sections, V. A. Maslov and O. V. Artyushkova decided to consider the Lower Devonian strata as independent units.

The Uskul' strata are located in the Uzynkyr subzone of the West-Magnitogorsk zone (Republic of Bashkortostan, the southwestern shore of the Uscul' Lake and the northwestern slope of the mountain of the same name). They are composed of volcaniclastic, carbonaceous and siliceous rocks, rarely volcanic rocks. The apparent thickness of the section is approximately $700 \mathrm{~m}$. For a long time, the age of the Uskul' strata was determined by the fauna from the lentiform limestones located in the upper part of the section. The article presents the first finds of macrofauna from a rhythmic packet of tephroturbidites lying in the lower part of the section. The fauna is represented by fossils of brachiopods and crinoids. Brachiopods correspond to the Early Devonian Pragian-Emsian age. The new data allow to speak about close time of sedimentation tephroturbidites and overlying limestones, and in general to determine the age of the Uscul' strata as Pragian-Early Emsian based on conodonts.

Keywords: Lower Devonian, biostratigraphy, macrofauna, Magnitogorsk megazone, Southern Urals.

\section{Введение}

Нижнедевонские отложения Западно-Магнитогорской зоны (3М3) представлены вулканокластическими, карбонатными и кремнистыми породами, реже вулканитами, которые отнесены к мансуровской, ильтибановской, ускульской и рыскужинской толщам. По причине макро- скопической схожести, недостаточности биостратиграфических данных и сложного тектонического строения территории долгое время данные толщи рассматривались в качестве первых подсвит ирендыкской свиты, которая сложена преимущественно вулканогенными и вулкано- 
генно-осадочными отложениями. После принятия новой Стратиграфической схемы Урала и проведения на изучаемой территории геолого-съемочных работ (ГДП-200) они вошли в состав мазовской свиты нижнего девона [7]. По результатам детальных стратиграфических исследований и геологического изучения девонских разрезов В. А. Масловым и О. В. Артюшковой было принято решение рассматривать нижнедевонские толщи в виде самостоятельных единиц [4].

Имеющиеся на сегодняшний день биостратиграфические данные, полученные преимущественно по карбонатным и кремнистым породам, не всегда позволяют детально установить время начала формирования вулканокластических пород, которые имеют наибольшее распространение среди нижнедевонских отложений. Связано это с фрагментарностью разрезов и не всегда понятными взаимоотношениями между вышеназванными породами. Помимо этого, практически не датирована нижняя часть нижнедевонских разрезов и не изучены взаимосвязи с более древними подстилающими породами. Следовательно, любые находки новой фауны представляют собой ценность для детализации возраста нижнедевонских отложений 3МЗ и понимания последовательности формирования слагающих их разных по составу пород.

\section{Строение разреза}

Ускульская толща расположена в Узынкырской подзоне 3М3, которая имеет сложное тектоническое строение, что, возможно, обусловило фрагментарность ее разреза и вторичные изменения пород. Толща сложена вул- канокластическими песчаниками и алевролитами, известняками, кремнисто-глинистыми сланцами, кремнями и, реже, вулканитами, которые лучше всего обнажены на югозападном берегу оз. Ускуль и северо-западном склоне одноименной горы Республики Башкортостан [1]. Видимая мощность всего разреза, который условно можно разделить на три интервала (рис. 1), составляет больше 700 м.

В первом интервале (в основании) наблюдаются разрозненные выходы массивных и брекчиевых плагиоклазовых и пироксен-плагиоклазовых порфиритов. Брекчиевые разности состоят из темно-фиолетовых, красновато-бурых и серо-зеленых угловатых фрагментов вулканитов (размер 0.5-20 см), погруженных в светло-серую зеленоватую цементирующую массу. Размер вкрапленников пироксена и плагиоклаза во всех порфиритах может достигать 2 мм. Вулканиты слагают потоки мощностью 3-5 и 10-15 м. Суммарная мощность их составляет на этом участке не более $100-150 \mathrm{M}$.

Во втором интервале (выше по разрезу) вулканиты перемежаются с пачками (15-25 м) ритмично чередующихся тефротурбидитов мощностью $0.1-0.15$ и $0.3-0.5$ м. Тефротурбидиты сложены серо-зелеными крупно-, средне- или мелкозернистыми песчаниками (иногда алевролитами) с градационной слоистостью, которые по направлению вверх постепенно сменяются тонкослоистыми аргиллитами. В алевроаргиллитах часто наблюдается слабоволнистая слоистость. Контакты между слоями тефротурбидитов резкие и плавно изогнутые. Эти породы могут чередоваться с серыми, темно-серыми тонкоплитчатыми, сильно выветрелыми кремнисто-глинистыми сланцами
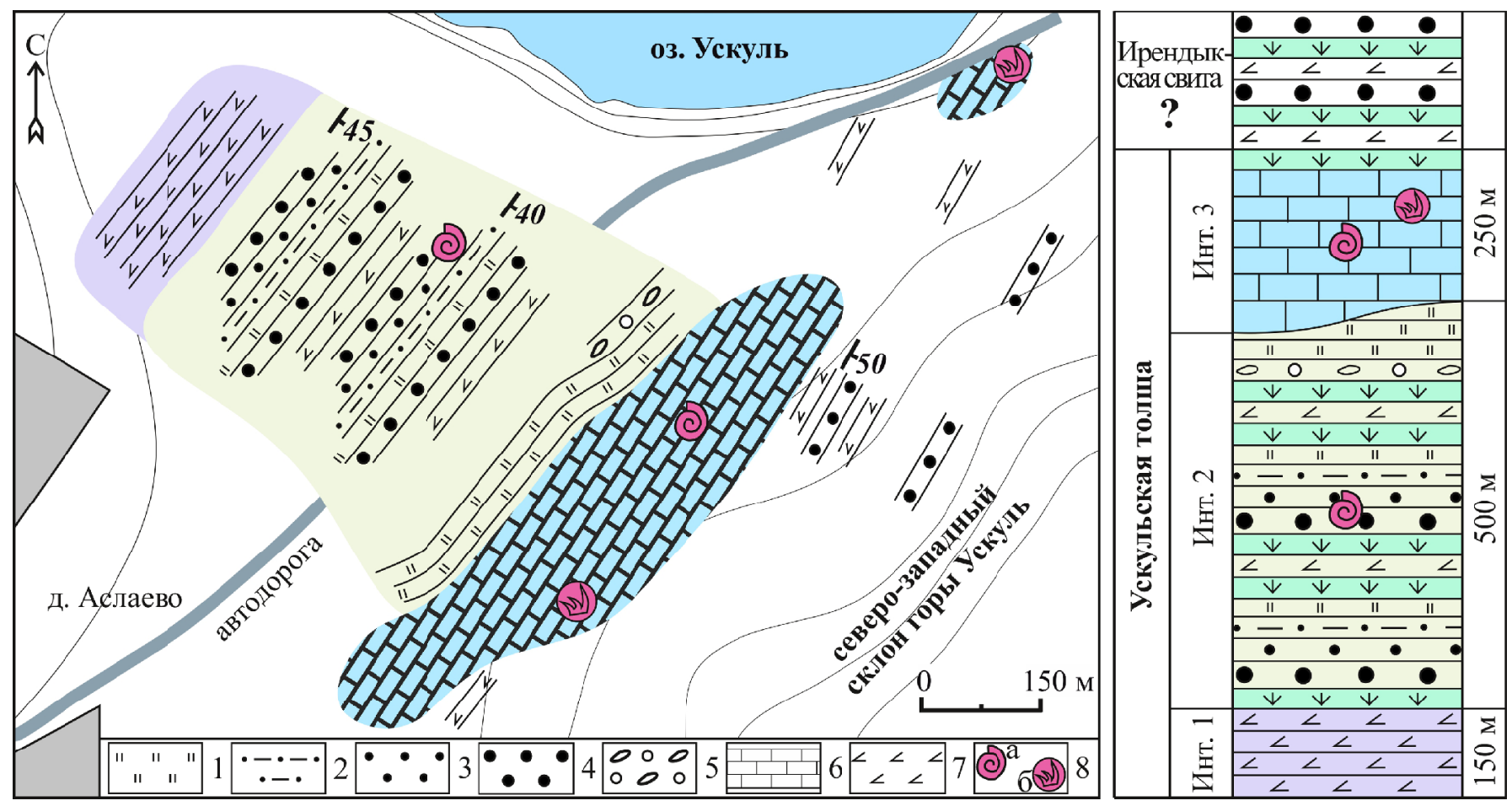

Рис. 1. Схематическая карта (слева) и литологическая колонка (справа) ускульской толщи.

Условные обозначения: 1 - аргиллиты, 2 - алевролиты, 3 - песчаники мелко- и среднезернистые, 4 - песчаники крупнозернистые, 5 - гравелиты, 6 - известняки, 7 - вулканиты (лавовые потоки), 8: а - точки находок брахиопод и криноидей, б - точки находок конодонтов [9]

Fig. 1. Schematic map (left) and lithological column (right) of the Uskul strata.

Legend: 1 - argillites, 2 - siltstones, 3 - fine- and medium-grained sandstones, 4 - coarse-grained sandstones, 5 - gravelites, 6 - limestones, 7 - volcanic rocks (lava flows), 8: a - points of brachiopod and crinoid finds, $b$ - points of conodont finds [9] 
мощностью 0.5-1 м. В ритмичной пачке кластолитов найдены остатки макрофауны и их отпечатки, которые будут описаны ниже. Заканчивается данный интервал разреза небольшими выходами гравелитов, грубозернистых вулканокластических песчаников и кремнисто-глинистых сланцев. Последние у подножья склона горы Ускуль слагают пачку мощностью 15-20 м.

Третий интервал разреза представлен светло-серыми, серыми, темно-серыми известняками, местами перекристаллизованными, мощностью 100-250 м. Контакты с окружающими их отложениями описаны М. Ш. Биковым, Ш. Н. Кацем и Б. М. Садрисламовым по-разному: как тектонические, согласные и несогласные. По данным В. А. Маслова и В. Б. Смирнова [5], известняки по простиранию постепенно сменяются кремнистыми отложениями. Подробное описание и обобщение накопленного материала по известнякам приводится в работе [8]. Подобные тела органогенных известняков, образующих блоки различной величины, прослеживаются субмеридионально на север и выходят на поверхность в районе дд. Баталово, Уразово, Ильтибаново, Юлдашево, Калканово и Шарипово и др.

\section{Стратиграфия}

Возраст пород ускульской толщи ранее был определен по известнякам, в которых в разные годы были найдены кораллы (табуляты и ругозы), криноидеи и брахиоподы пражско-раннеэмсского возраста (ссылки на первоисточники приведены в работе [4]). Возраст брахиопод, найденных В. А. Масловым в 1965 году и определенных А. П. Тяжевой, был пересмотрен Л. И. Мизенс согласно современной региональной стратиграфической схеме Урала. Были установлены представители Gypidula ex gr. biplicata (Schnur), G. subvenetus Khod., Multicosta? sp., Kransia ? sp., Punctatrypa cf. perpolita (Khod.), Carinatina sp., Plesicarinatina cf. mala (Khod.), Totia ex gr. intermediafera (Khod.), Karpinskia conjugula (Tschern.), Mimatrypa ? sp., Ilmenia cf. waganovi I. Breiv. Данный комплекс брахиопод характерен для пражско-нижнеэйфельского стратиграфического интервала.
Аналогичный возраст также был установлен по конодонтам [9], полученным из разных частей известняков. В первой точке с координатами N5351'13.32" Е5849'51.89", находящейся к югу от озера Ускуль, обнаружены Polygnathus pireneae Boersma и Pandorinellina aff. miae (Bultynck), характерные для верхней части пражского и низов эмсского ярусов нижнего девона (зона pireneae низы зоны kitabicus). Во второй точке с координатами N5351'34.77" E58 50'24.23", расположенной на юго-восточном берегу того же озера, найдены единичные конодонты неполной сохранности Polygnathus aff. gilberti Bardashev и Caudicriodus aff. sigmoidalis (Carls et Gandl), характерные для нижней части эмсского яруса [9].

Дополнительная макрофауна найдена в разнозернистых тефротурбидитах, расположенных в нижней части разреза (рис.1), в небольшом карьере по добыче камня (координаты: N5351'393" E5849'672"). Здесь снизу вверх по разрезу наблюдаются:

1. Серо-зеленые однородные массивные средне- и крупнозернистые вулканокластические песчаники. Мощность $0.2-0.3 \mathrm{M}$.

2. Тефротурбидит, который в основании сложен серо-зелеными гравелитами и грубозернистыми вулканокластическими песчаниками с обильным количеством обломков светло-серых известняков и темно-серых, черных кремней разной размерности (1-5 мм и более). В данном слое собраны брахиоподы (рис. 2, 3, a-d) и криноидеи (рис. 3, е-h). Размер брахиопод составляет 0.5-2 см, а криноидей - от первых мм до 0.5-1 см. Мощность слоя 0.3 м. Перекрывается данный слой крупно- и среднезернистыми песчаниками с заметно меньшим количеством макрофауны (мощность слоя 0.2 м), которые, в свою очередь, сменяются мелкозернистыми песчаниками, алевролитами и кремнистыми аргиллитами (мощность слоя 0.4 м). Азимут падения пород: ЮВ $-110^{\circ}$, угол $-70^{\circ}$, мощность тефротурбидита составляет $0.9-1$ м.

3. Тефротурбидит, который в нижней части состоит из крупно- и мелкозернистых гравелитов, постепенно

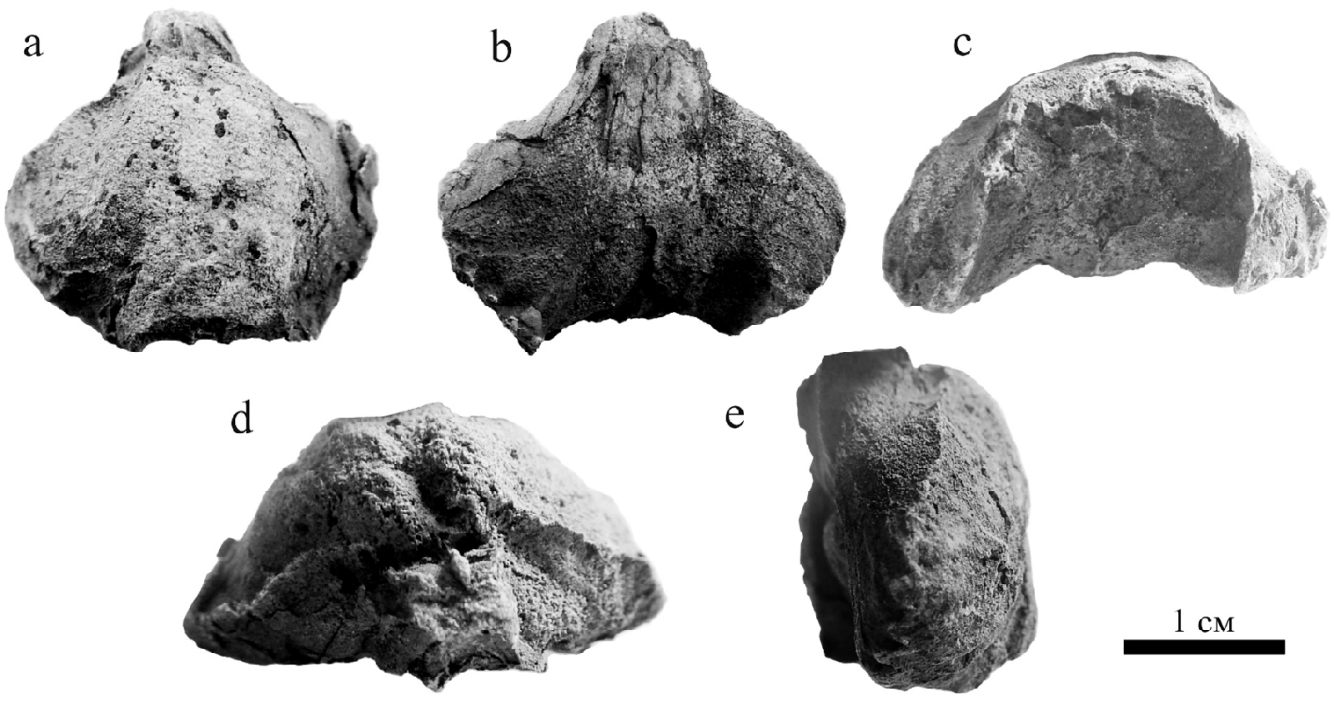

Рис. 2. Внутреннее ядро раковины брахиоподы отряда Rhynchonellida: a - спинная створка, b - брюшная створка, c - передний край, d - замочный край; e - вид сбоку

Fig. 2. The internal cast of the brachiopod of the order Rhynchonellida: $\mathrm{a}-$ the dorsal valve, $\mathrm{b}-$ the ventral valve, $\mathrm{c}-$ the anterior view, $\mathrm{d}-$ the hinge view; $\mathrm{e}-$ the lateral view 

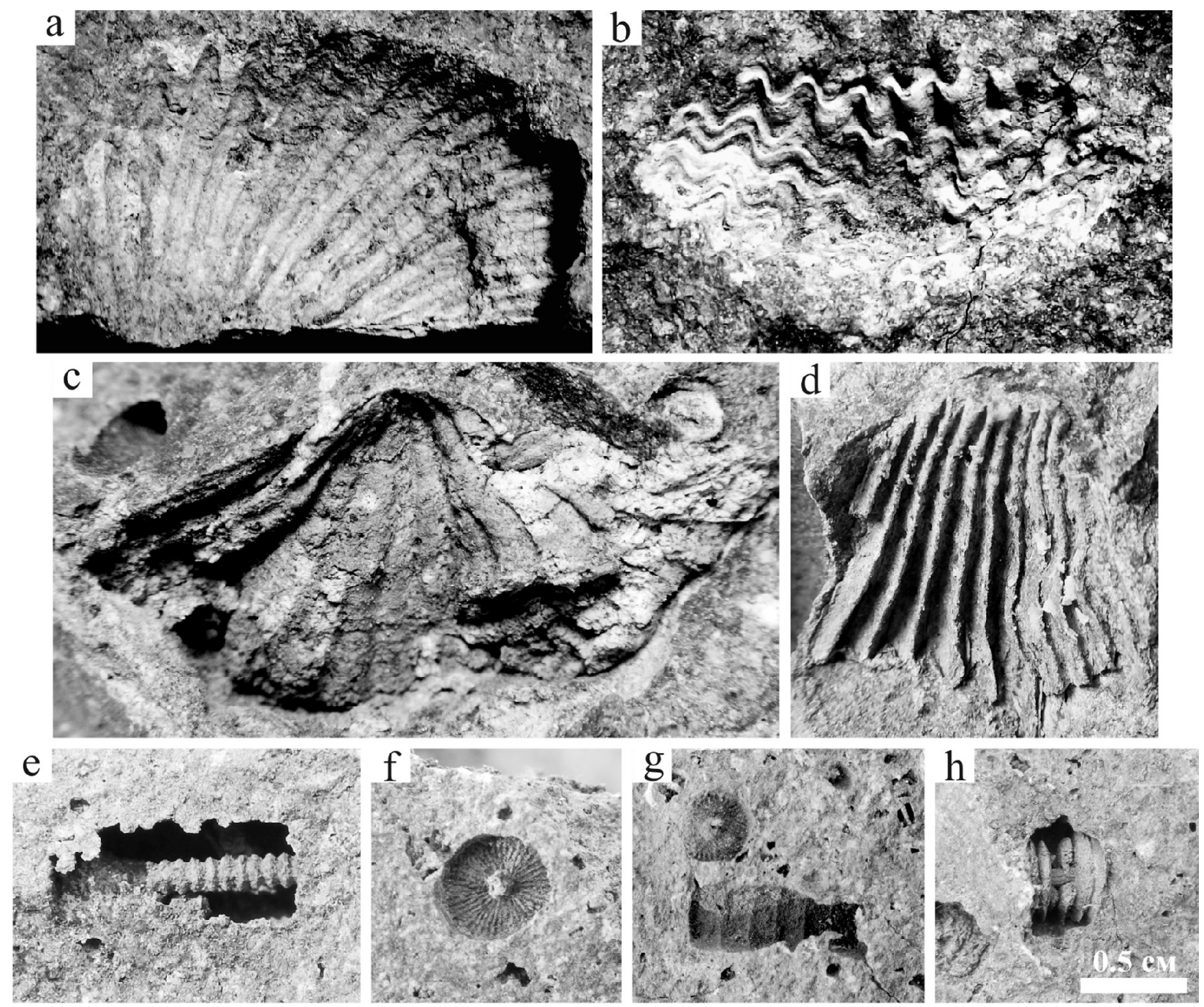

Рис. 3. Отпечатки брахиопод и криноидей: a - Totia ex gr. intermediafera (Khod.): отпечаток неполной спинной створки; b - Spinatrypa ? sp.: отпечаток переднего края; c - Neospirigerina ? sp.: отпечаток неполной спинной створки; $\mathrm{d}-$ Wilsonella $? \mathrm{sp} .:$ отпечаток неполной спинной створки; $\mathrm{e}-\mathrm{h}$ - отпечатки члеников криноидей. Масштабная линейка указана для всех рисунков

Fig. 3. External cast of brachiopods and prints of crinoids: a - Totia ex gr. intermediafera (Khod.): incomplete dorsal valve; b - Spinatrypa ? sp .: the anterior margin; $\mathrm{c}-$ Neospirigerina ? sp.: incomplete dorsal valve; $\mathrm{d}-$ Wilsonella ? sp.: incomplete dorsal valve; e- $\mathrm{h}-\mathrm{segments}$ of crinoids. A scale bar is shown for all figures

сменяющихся грубозернистыми песчаниками. В верхней части турбидит представлен крупнозернистым песчаником. Макрофауны мало. Мощность 0.6 м.

4. Тефротурбидит, сложенный гравелитами с обломками кремней, известняков и макрофауны небольшой размерности, постепенно сменяющимися грубо-, крупно-, мелкозернистыми песчаниками и алевролитами. Мощность $0.5-0.6 \mathrm{м}$.

Найденные в вышеописанных породах отпечатки брюшных и спинных створок брахиопод определены как Wilsoniella ? sp., Spinatrypa ? sp., Neospirigerina ? sp., Totia ex gr. intermediafera (Khod.), что позволяет говорить о раннедевонском пражско-эмсском возрасте вмещающих их отложений.

\section{Выводы}

Новые находки фауны позволяют уточнить возраст нижней части ускульской толщи и условия формирования слагающих ее вулканокластических отложений. Согласно ранее проведенным реконструкциям [1], накопление их происходило совместно с вышележащими «ри- фогенными» известняками в едином раннедевонском островодужном бассейне. Карбонатонакопление иногда прерывалось поступлением пирокластики в бассейн седиментации и действием тефротурбидитов, что в определенной степени подтверждается наличием прослоев вулканокластического материала в известняках у дд. Баталово и Рыскужино [3]. Турбидные потоки, насыщенные тефровым материалом (тефротурбидиты), перемещались по склонам юной островной дуги и частично разрушали карбонатные постройки с макрофауной, которые располагались, по-видимому, на пологих мелководных участках рельефа. Таким образом, новая макрофауна, найденная в тефротурбидитах, позволяет говорить о близком по геологическим меркам времени их формирования с вышележащими известняками и констатировать возраст ускульской толщи в целом как пражско-раннеэмсский. Аналогичным образом происходило формирование в южной части бассейна отложений рыскужинской толщи, в вулканокластических разностях которой также найдены [2, 6] переотложенные брахиоподы раннеэмсского возраста. 
Исследования выполнены в рамках темы № 0246-20190118 государственного задания ИГ УФИЦ РАН «Границы стратиграфических подразделений фанерозоя как отражение региональных и глобальных биотических и абиотических событий» (Р. И. Зайнуллин) и № АAАA-A18-118052590032-6 государственного задания ИГГ УрО РАН «Палеогеодинамика и эволюиия структурно-вещественных комплексов при формировании земной коры континентального типа на примере Урало-Монгольского складчатого пояса и Западно-Сибирской платформы» (Л. И. Мизенс, А. Г. Мизенс).

Авторы благодарят к. г-м. н. А.М. Фазлиахметова за организацию экспедиционных выездов, д. г-м. н. В. А. Маслова за ознакомление с нижнедевонскими разрезами и д. г-м. н. O. В. Артюшкову (все ИГ УФИЦ РАН) за ценные замечания no cmambe.

\section{Литература}

1. Зайнуллин Р. И. Обстановки седиментации лохковнижнеэмсских вулканокластических отложений ЗападноМагнитогорской зоны Южного Урала // Известия Томского политехнического университета. Инжиниринг георесурсов. 2018. № 12. С. 104-113.

2. Иванов К. С., Бикбаев А. З., Мизенс Л. И., Сапельни-

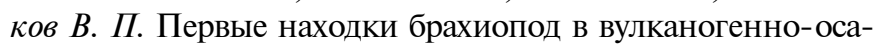
дочных породах ирендыкской свиты на Южном Урале // Ежегодник- 1996: Информационный сборник научных трудов. Екатеринбург: ИГГ УрО РАН, 1997. С. 13-15.

3. Каи Ш. Н. Отчет о геологическом доизучении в масштабе 1:50000 Миндякской площади (Планшеты N-40-70Г-б, в, г; N-40-71-А и В; N-40-82-А-б, в,г и Б): по работам Миндякского геолого-съемочного отряда и Учалинской геофизической партии за 1975-1980 годы. Уфа, 1980. Инв. № 10492.

4. Маслов В. А., Артюшкова О. В. Стратиграфия и корреляция девонских отложений Магнитогорской мегазоны Южного Урала. Уфа: ДизайнПолиграфСервис, 2010. $288 \mathrm{c}$.

5. Маслов В. А., Смирнов В. Б. Типовые разрезы силура и девона Магнитогорского мегасинклинория: Отчет // Типовые разрезы палеозоя Магнитогорского мегасинклинория. Раздел 1 (силур и девон). Уфа, 1970, 333 с. Инв. № 7999.

6. Сапельников В. П., Мизенс Л. И., Иванов К. С., Бикбаев $A$. З. Брахиоподы из туфопесчаников ирендыкской свиты (нижний эмс, Южный Урал) // Материалы по стратиграфии и палеонтологии Урала. Сборник научных трудов. Выпуск 2. Екатеринбург, 1999. С. 149-159.

7. Стратиграфические схемы Урала (докембрий, палеозой) / МСК России. Екатеринбург, 1993. 151 с.

8. Фазлиахметов A. М. Нижнедевонские известняки района озера Ускуль (север Западно-Магнитогорской зоны Южного Урала) // Геология, геоэкология и ресурсный потенциал Урала и сопредельных территорий: Материалы III Всероссийской молодежной геологической конференции. Уфа, ИГ УНЦ РАН, 2015. С. 99-103.

9. Фазлиахметов А. М., Артюшкова О. В. Условия формирования раннеэмсских известняков восточного склона Южного Урала по геохимическим данным // Ocaдочная геология Урала и прилежащих регионов: сегодня и завтра: Материалы 12 Уральского литологического совещания. Екатеринбург, ИГГ УрО РАН, 2018. С. 355-359.

\section{References}

1. Zainullin R. I. Obstanovki sedimentatsii lokhkovnizhneemsskikh vulkanoklasticheskikh otlozheniy ZapadnoMagnitogorskoy zony Yuzhnogo Urala (Sedimentation of Lochkovian Lower Emsian volcanoklastic deposits of the WestMagnitogorsk zone of the South Ura) Bulletin of the Tomsk Polytechnic University. Geo Assets Engineering, 2018, V. 329, No. 12, pp. 104-113.

2. Ivanov K. S., Bikbaev A. Z., Mizens L. I., Sapelnikov V. P. Pervye nakhodki brakhiopod v vulkanogenno-osadochnykh porodakh irendykskoy svity na Yuzhnom Urale (The first finds of brachiopods in volcanogenic-sedimentary rocks of the Irendyk suite in the Southern Urals). Ezhegodnik-1996. Collection of articles. Ekaterinburg, IGG UB RAS, 1997, pp. 13-15.

3. Katz Sh. N. Otchet o geologicheskom doizuchenii $v$ masshtabe 1:50000 Mindyakskoy ploshchadi (Planshety N-4070-G, b,v,g; N-40-71-A i B; $N$-40-82-A-b,v,g i B): po rabotam Mindyakskogo geologos" yemochnogo otryada $i$ Uchalinskoy geofizicheskoy partii za 1975-1980 gody (Report on geological prospecting on a scale of 1: 50,000 in Mindyak Square (Tablets N-40-70-G, b,v, g; N-40-71-A and B; N-40-82- A-b,v, g and $\mathrm{B})$ : on the works of the Mindyak geological survey unit and the Uchalinsky geophysical party for the years 1975-1980). Ufa, 1980, inv. No. 10492.

4. Maslov V. A., Artyushkova O. V. Stratigrafiya $i$ korrelyatsiya devonskikh otlozheniy Magnitogorskoy megazony Yuzhnogo Urala (Stratigraphy and correlation deposits of Devonian of the Magnitogorsk megazone of Southern Urals). Ufa: DizaynPoligrafServis Publ., 2010, 288 p.

5. Maslov V. A., Smirnov V. B. Tipovye razrezy silura $i$ devona Magnitogorskogo megasinklinoriya (Typical sections of the Silurian and the Devonian of the Magnitogorsk megasynclinorium). Report on the topic: «Typical sections of the Paleozoic of the Magnitogorsk megasynclinorium». Section 1 (Silurian and Devonian). Ufa, 1970, 333 p, Inv. No. 7999.

6. Sapelnikov V. P., Mizens L.I., Ivanov K. S., Bikbaev A. Z. Brakhiopody iz tufopeschanikov irendykskoy svity (nizhniy ems, Yuzhnyy Ural) (Brachiopods from tuff sandstones of the Irendyk suite (Lower Emsian, South Urals)). Materialy po stratigrafii i paleontologii Urala (Materials on stratigraphy and paleontology of the Urals). Colection of articles. Issue 2. Ekaterinburg, 1999, pp. 149-159.

7. Stratigraficheskie skhemy Urala (dokembriy, paleozoy) (Stratigraphic schemes of the Urals (Precambrian, Paleozoic)). MSC, Ekaterinburg, 1993, 151 p.

8. Fazliakhmetov A. M. Nizhnedevonskie izvestnyaki rayona ozera Uskul' (sever Zapadno-Magnitogorskoy zony Yuzhnogo Urala) (Lower Devonian limestones of the Uskul Lake region (north of the West Magnitogorsk zone of the Southern Urals). Proceedings of conference. Ufa, IG USC RAS, 2015, pp. 99103.

9. Fazliakhmetov A. M., Artyushkova O. V. Usloviya formirovaniya ranneemsskikh izvestnyakov vostochnogo sklona Yuzhnogo Urala po geokhimicheskim dannym (Formation conditions of Early Emsian limestones of the eastern slope of the Southern Urals according to geochemical data). Osadochnaya geologiya Urala i prilezhashchikh regionov: segodnya $i$ zavtra (Sedimentary geology of the Urals) Proceedings of conference. Ekaterinburg, IGG UB RAS, 2018, pp. 355359. 